\title{
Evaluation of the Circulation Patterns in the Black Sea Using Remotely Sensed and in Situ Measurements
}

\author{
Robert Toderascu, Eugen Rusu \\ Department of Applied Mechanics, "Dunarea de Jos" University of Galati, Galati, Romania \\ Email: Robert.Toderascu@ugal.ro
}

Received June 16, 2013; revised July 19, 2013; accepted August 15, 2013

Copyright (C) 2013 Robert Toderascu, Eugen Rusu. This is an open access article distributed under the Creative Commons Attribution License, which permits unrestricted use, distribution, and reproduction in any medium, provided the original work is properly cited.

\begin{abstract}
The objective of the present work is to provide an overview of the general circulation features in the Black Sea basin. In order to achieve this, 18 years (1993-2010) of satellite data coming from the Aviso website were analyzed. A description of the general circulation patterns in the Black Sea is first presented. This is followed by statistical analyses of the satellite data in 20 points covering the entire area of the sea. The reference points were chosen as follows: 12 points along the Rim cyclonic current, 3 points inside the Rim cyclonic current, 4 points on the edge of two of the biggest anticyclonic gyres outside the Rim current and one point in the northwestern shelf area of the basin. Rose graphics were drawn for the reference points for winter and summer time. Finally, 9 years of in situ data obtained from the Gloria drilling platform were analyzed and compared with the satellite data. The present study shows that most of the reference points are sensitive to seasonal changes. The current velocities depend mostly on the points location: the points located on the Rim current and on the nearshore anticyclonic eddies present higher values than the ones located in or outside the general circulation features.
\end{abstract}

Keywords: Black Sea; Circulation Patterns; Statistical Analyses; Rose Graphics

\section{Introduction}

The Black Sea is an enclosed sea situated between Europe, Anatolia and Caucasus, bounded by the $40.56^{\circ} \mathrm{N}$ and $46.33^{\circ} \mathrm{N}$ latitude and $27.27^{\circ} \mathrm{E}-41.42^{\circ} \mathrm{E}$ longitude. It is the second enclosed sea on Earth after the Caspian Sea, with a surface of $423,000 \mathrm{~km}^{2}$. The only connection bounding the Black Sea to the Global Ocean is by the Bosphorus strait, a 0.7 - 3.5 narrow channel with $31 \mathrm{~km}$ in length and a depth that can vary from 39 to $100 \mathrm{~m}$.

The sea contains three vertical water layers that do not mix, the bottom one being the largest anoxic water body on Earth. The surface layer is located on the sea surface, spreading to $50 \mathrm{~m}$ depth and is the most active water layer of the sea. It responds strongly to the seasonal temperature variations and wind fields. The second layer is the cold intermediate layer located at depths that vary from 50 to $180 \mathrm{~m}$. Its most significant characteristic feature is the fact that the temperature here is constant, between $6^{\circ} \mathrm{C}$ and $8^{\circ} \mathrm{C}$, not being affected by the temperature changes in the surface layer. The cold intermediate layer is formed by the convective processes associated with the winter cooling of the surface waters [1-3]. Below the intermediate cold layer is the bottom layer where waters are mostly stagnant showing small changes in properties, except near boundaries. In the depths higher than $1700 \mathrm{~m}$, the bottom layer is subjected to geothermal heating from the sea floor, the temperature being about $8.8^{\circ} \mathrm{C}$ [4]. The maximum depth of the Black Sea is of $2588 \mathrm{~m}$. However, these are isolated points located in the south and southeast of the basin. The average maximum depth of the sea is $2100 \mathrm{~m}$.

The Black Sea's salinity is lower than that in the open seas or in the oceans, due to the enclosed state and high river discharges. The average salinity in the Black Sea is 18.2 PSU, but it can be much lower near the river discharges. The bottom layer's salinity, however, has increased values by an average of 21.8 PSU. This difference is maintained due to the fact that the surface and bottom waters do not mix, and the lower layer is receiving more saline waters from the Mediterranean Sea. Moreover, the surface layer is exposed to rain, river discharges and dilution.

The cyclonic character of the Black Sea circulation resulting from the cyclonic state of the wind field patterns was first described by Knipovich [6] Later on Filipov [7], Boguslavskiy et al. [8], Blatov et al. [9], Stanev et al. [10], Stanev [11] and Eremeev et al. [12] 
provided valuable details regarding the sea circulation patterns. However, the model proposed did not contribute to a significant change to Knipovich's classical circulation model.

The northwestern shelf of the sea consists of a close to $200 \mathrm{~km}$ wide shelf that receives the fresh water input from Danube, Dniestr and Dniepr rivers. The surface circulation is characterized by a persistent cyclonic coastal current referred to as the Rim current, with a width of over $75 \mathrm{~km}$ and an average speed of $0.2 \mathrm{~ms}^{-1}$ at the surface [13]. Between the Rim current and the coast, a number of seasonal anticyclonic eddies are formed. While the Rim current meanders eastward along the Anatolian coast, it forms two anticyclonic coastal eddies that were identified and labeled by Oguz et al. [14] as the Sinop and Kizilirmak eddies. In the eastern area of the basin, the Batumi eddy is formed. The Rim current flows along the Caucasian coast to the narrow continental slope, meandering in the form of backward curling. The jet separates three cyclonic eddies of the eastern basin that constitute the multiple cells of the Eastern Basin Cyclonic Gyre [13]. In the coastal side of the offshore jet, a small anticyclonic eddy is formed, called the Caucasian eddy. The Rim current continues to meander to the south of the Crimean Peninsula between two larger coastal anticyclonic eddies and two cyclonic eddies located in the central part of the basin. The anticyclonic eddies located on the northern side are referred as the Crimean Eddy and Sevastopol Eddy, respectively [13].

While it proceeds southwest towards the Bosphorus area, the Rim current creates the Bosphorus eddy. A small anticyclonic eddy is formed in the western area of the Black Sea basin, between Sevastopol and Bosphorus eddies, labeled as Kali-Akra. Its basin-wide circulation is closed with the Sakarya eddy, situated in the southwest area.

Among the above mentioned eddies, Batumi and Se- vastopol are the most permanent and largest mesoscale structures $[15,16]$. Figure 1 presents a scheme of the Black Sea surface circulation as discussed above. The solid lines indicate the recurrent features of the general circulation.

\section{Statistical Analysis of the Circulation Patterns Using Satellite Data}

In order to achieve a better understanding of the current fields in the Black Sea basin and of their time and space variations, 18 years of satellite data were analyzed, covering the time period 1993-2010. The satellite data were obtained from Aviso website [17] and contains daily measurements of the $\mathrm{U}$ and $\mathrm{V}$ components of the currents with a spatial resolution of approximately $10 \mathrm{~km}$ on the horizontal and of $13 \mathrm{~km}$ on the vertical.

20 reference points were considered in the present analysis, as shown in Figure 2. The first 12 points ( $\mathrm{P} 1$, $\mathrm{P} 2, \ldots \mathrm{P} 12$ ) were considered on the Rim current (with red), points P13-P15 were located inside the Rim cyclonic current (with purple), points P16, P17 at the edge of the Batumi eddy, P18, P19 at the edge of the Sinop eddy (with green) and point P20 was located on the northwestern shelf area of the Black Sea basin (with orange). In Table 1 the coordinates of the reference points are presented, along with the monthly averaged values of current velocities. Table 2 shows the statistical analyses for the reference points considering the following parameters: minimum, maximum, mean and median values, standard deviation, skewness and kurtosis. In Table 3, percentile analyses regarding the 50th and 95th percentiles are presented for the reference points considered, grouped in winter and summer time, respectively where winter time is the six month period from October to March and summer from April to September.

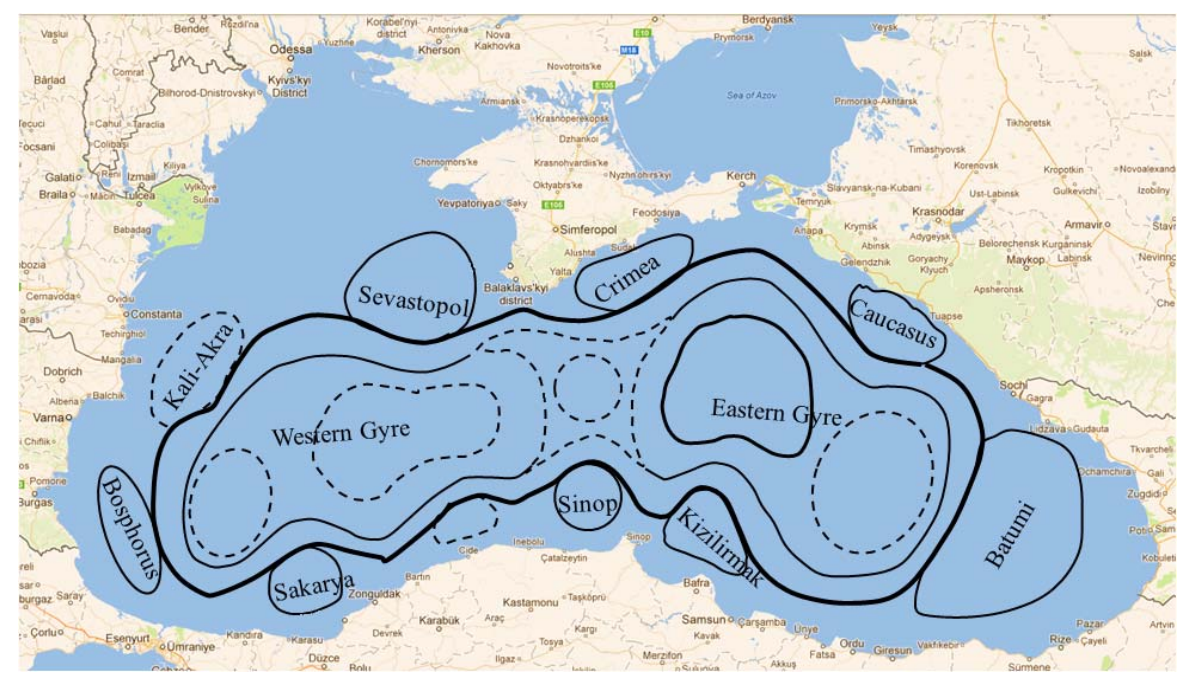

Figure 1. Schematic of the Black Sea surface circulation. The solid lines indicate recurrent features of the general circulation. 


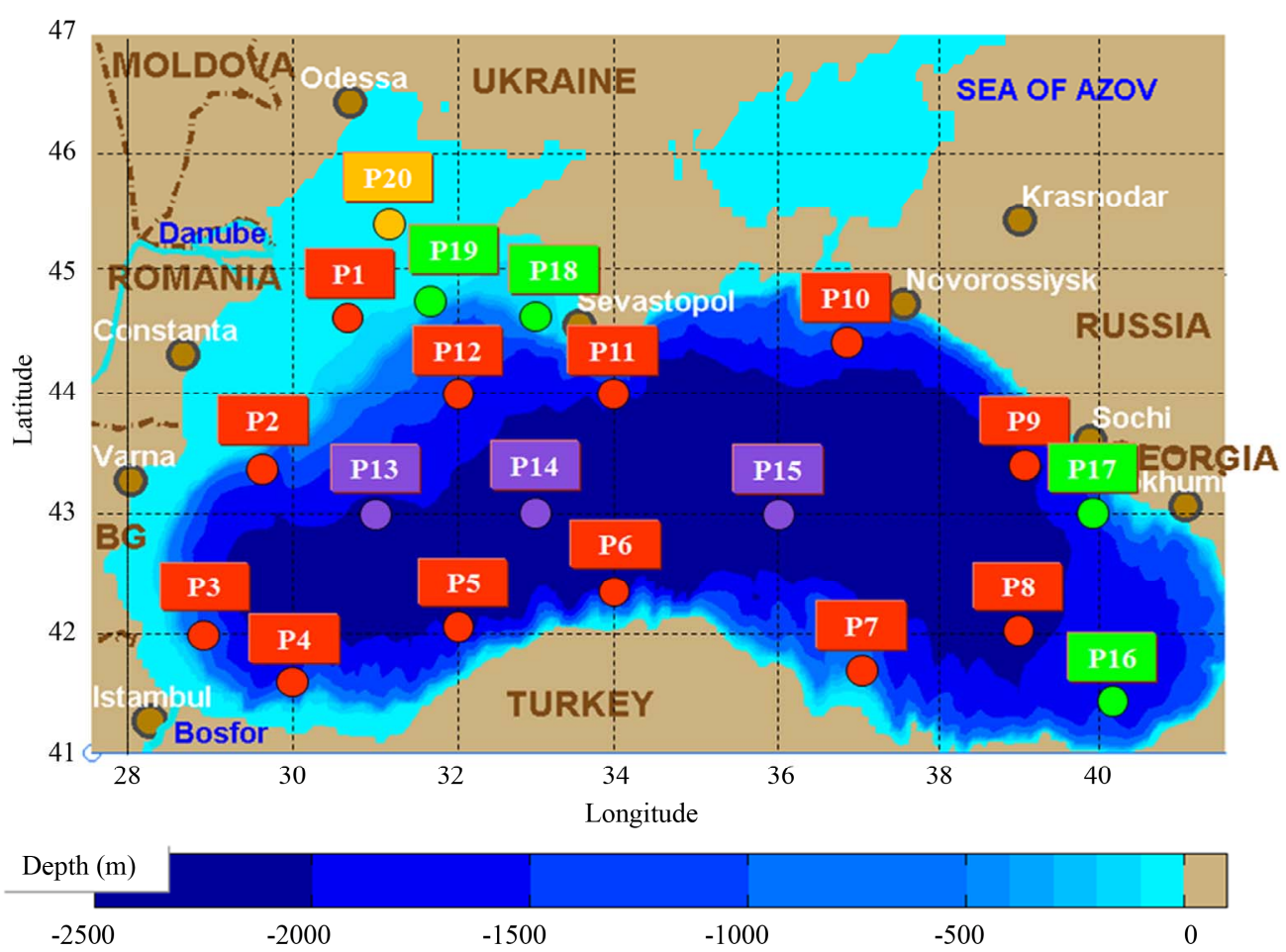

Figure 2. The bathymetric map of the Black Sea with the location of the 20 reference points as follows: red-points located on the Rim cyclonic current, purple - points located inside the Rim current, green — points located at the edge of the anticyclonic eddies, orange - point located in the northwestern shelf area of the sea.

Table 1. Monthly averaged values of the current velocity $\left(\mathrm{ms}^{-1}\right)$ for the reference points $(\mathrm{P1}, \mathrm{P2}, \ldots$ P20) for the period $1993-2010$.

\begin{tabular}{|c|c|c|c|c|c|c|c|c|c|c|c|c|}
\hline \multirow{2}{*}{ Points (coordinates) } & \multicolumn{12}{|c|}{ Month } \\
\hline & Jan. & Feb. & Mar. & Apr. & May & Jun. & Jul. & Aug. & Sep. & Oct. & Nov. & Dec. \\
\hline $\mathrm{P} 1(44.4 \mathrm{~N}, 30.43 \mathrm{E})$ & 0.075 & 0.074 & 0.073 & 0.079 & 0.079 & 0.075 & 0.066 & 0.063 & 0.056 & 0.057 & 0.062 & 0.069 \\
\hline $\mathrm{P} 2(43.18 \mathrm{~N}, 29.43 \mathrm{E})$ & 0.106 & 0.119 & 0.133 & 0.125 & 0.112 & 0.111 & 0.087 & 0.108 & 0.111 & 0.107 & 0.100 & 0.113 \\
\hline P3 (41.58N, 29E) & 0.133 & 0.125 & 0.126 & 0.106 & 0.096 & 0.095 & 0.108 & 0.119 & 0.110 & 0.096 & 0.110 & 0.102 \\
\hline $\mathrm{P} 4(41.36 \mathrm{~N}, 29.58 \mathrm{E})$ & 0.078 & 0.082 & 0.083 & 0.093 & 0.074 & 0.074 & 0.073 & 0.077 & 0.085 & 0.078 & 0.082 & 0.087 \\
\hline P5 (42.7N, 31.59E) & 0.061 & 0.056 & 0.059 & 0.067 & 0.067 & 0.061 & 0.059 & 0.052 & 0.058 & 0.076 & 0.078 & 0.070 \\
\hline P6 (42.21N, 34.2E) & 0.076 & 0.080 & 0.077 & 0.070 & 0.077 & 0.074 & 0.071 & 0.076 & 0.069 & 0.069 & 0.072 & 0.068 \\
\hline P7 (41.32N, 36.59E) & 0.068 & 0.097 & 0.083 & 0.081 & 0.064 & 0.063 & 0.069 & 0.073 & 0.081 & 0.078 & 0.077 & 0.082 \\
\hline P8 (42.1N, 39.3E) & 0.143 & 0.097 & 0.098 & 0.097 & 0.095 & 0.106 & 0.122 & 0.134 & 0.128 & 0.115 & 0.121 & 0.131 \\
\hline P9 (43.32N, 39.14E) & 0.127 & 0.115 & 0.111 & 0.110 & 0.116 & 0.103 & 0.101 & 0.126 & 0.119 & 0.110 & 0.125 & 0.122 \\
\hline $\mathrm{P} 10(44.38 \mathrm{~N}, 36.49 \mathrm{E})$ & 0.155 & 0.145 & 0.137 & 0.133 & 0.105 & 0.108 & 0.134 & 0.126 & 0.145 & 0.149 & 0.133 & 0.135 \\
\hline $\mathrm{P} 11(43.59 \mathrm{~N}, 33.59 \mathrm{E})$ & 0.080 & 0.075 & 0.068 & 0.071 & 0.069 & 0.071 & 0.064 & 0.063 & 0.079 & 0.078 & 0.078 & 0.073 \\
\hline $\mathrm{P} 12(44 \mathrm{~N}, 32 \mathrm{E})$ & 0.149 & 0.137 & 0.162 & 0.179 & 0.168 & 0.159 & 0.152 & 0.125 & 0.128 & 0.139 & 0.124 & 0.139 \\
\hline P13 (43N, 30.59E) & 0.070 & 0.091 & 0.080 & 0.076 & 0.084 & 0.083 & 0.074 & 0.074 & 0.082 & 0.088 & 0.096 & 0.081 \\
\hline $\mathrm{P} 14(43.1 \mathrm{~N}, 32.58 \mathrm{E})$ & 0.066 & 0.059 & 0.073 & 0.075 & 0.064 & 0.069 & 0.064 & 0.072 & 0.061 & 0.071 & 0.065 & 0.068 \\
\hline $\mathrm{P} 15(42.59 \mathrm{~N}, 36 \mathrm{E})$ & 0.081 & 0.082 & 0.083 & 0.076 & 0.068 & 0.079 & 0.085 & 0.090 & 0.087 & 0.091 & 0.092 & 0.081 \\
\hline $\mathrm{P} 16(41.23 \mathrm{~N}, 40.4 \mathrm{E})$ & 0.108 & 0.101 & 0.106 & 0.105 & 0.112 & 0.121 & 0.113 & 0.108 & 0.108 & 0.108 & 0.097 & 0.112 \\
\hline P17 (43.32N, 39.57E) & 0.117 & 0.083 & 0.094 & 0.089 & 0.102 & 0.088 & 0.091 & 0.095 & 0.107 & 0.137 & 0.144 & 0.125 \\
\hline P18 (44.37N, 33E) & 0.116 & 0.123 & 0.122 & 0.097 & 0.103 & 0.097 & 0.102 & 0.089 & 0.116 & 0.116 & 0.101 & 0.119 \\
\hline $\mathrm{P} 19$ (44.4N, 31.46E) & 0.181 & 0.181 & 0.183 & 0.169 & 0.161 & 0.176 & 0.174 & 0.144 & 0.137 & 0.128 & 0.137 & 0.158 \\
\hline $\mathrm{P} 20(45.21 \mathrm{~N}, 31 \mathrm{E})$ & 0.071 & 0.075 & 0.068 & 0.057 & 0.064 & 0.058 & 0.062 & 0.073 & 0.069 & 0.076 & 0.080 & 0.069 \\
\hline
\end{tabular}


Table 2. Current velocity statistics for the reference points (P1, P2, ... P20) in the Black Sea basin.

\begin{tabular}{|c|c|c|c|c|c|c|c|}
\hline $\mathrm{Nr}$ of points $=6672$ & $\operatorname{Minimum}\left(\mathrm{ms}^{-1}\right)$ & $\operatorname{Maximum}\left(\mathrm{ms}^{-1}\right)$ & $\operatorname{Mean}\left(\mathrm{ms}^{-1}\right)$ & $\operatorname{Median}\left(\mathrm{ms}^{-1}\right)$ & St. Dev $\left(\mathrm{ms}^{-1}\right)$ & Skewness & Kurtosis \\
\hline $\mathrm{P} 1$ & 0.001 & 0.342 & 0.069 & 0.062 & 0.041 & 1.184 & 5.455 \\
\hline P2 & 0.001 & 0.454 & 0.111 & 0.094 & 0.071 & 1.207 & 4.609 \\
\hline $\mathrm{P} 3$ & 0.001 & 0.463 & 0.110 & 0.097 & 0.068 & 1.255 & 5.357 \\
\hline P4 & 0.001 & 0.293 & 0.080 & 0.071 & 0.048 & 1.076 & 4.339 \\
\hline P5 & 0.000 & 0.438 & 0.063 & 0.056 & 0.040 & 1.633 & 10.307 \\
\hline P6 & 0.000 & 0.227 & 0.073 & 0.068 & 0.040 & 0.742 & 3.420 \\
\hline P7 & 0.000 & 0.313 & 0.076 & 0.070 & 0.045 & 1.158 & 5.266 \\
\hline P8 & 0.002 & 0.429 & 0.117 & 0.105 & 0.067 & 1.024 & 4.360 \\
\hline P9 & 0.003 & 0.429 & 0.116 & 0.103 & 0.070 & 0.980 & 3.898 \\
\hline $\mathrm{P} 10$ & 0.001 & 0.417 & 0.133 & 0.119 & 0.077 & 0.870 & 3.500 \\
\hline P11 & 0.001 & 0.365 & 0.072 & 0.066 & 0.041 & 1.215 & 6.219 \\
\hline $\mathrm{P} 12$ & 0.002 & 0.558 & 0.146 & 0.131 & 0.083 & 0.992 & 4.410 \\
\hline P13 & 0.001 & 0.354 & 0.081 & 0.070 & 0.054 & 1.598 & 6.570 \\
\hline P14 & 0.001 & 0.308 & 0.068 & 0.063 & 0.037 & 1.040 & 5.278 \\
\hline P15 & 0.001 & 0.370 & 0.082 & 0.072 & 0.049 & 1.199 & 5.154 \\
\hline P16 & 0.002 & 0.427 & 0.109 & 0.100 & 0.059 & 0.949 & 4.285 \\
\hline P17 & 0.001 & 0.626 & 0.106 & 0.094 & 0.068 & 1.699 & 8.971 \\
\hline P18 & 0.001 & 0.396 & 0.108 & 0.098 & 0.064 & 0.849 & 3.668 \\
\hline P19 & 0.003 & 0.588 & 0.160 & 0.151 & 0.083 & 0.635 & 3.388 \\
\hline P20 & 0.001 & 0.293 & 0.069 & 0.063 & 0.039 & 0.992 & 4.577 \\
\hline
\end{tabular}

Table 3. Percentile analysis for the reference points (P1, P2, ... P20) in the Black Sea for summer and winter time, respectively the second quartile and the 95th percentile.

\begin{tabular}{|c|c|c|c|c|c|c|c|c|c|}
\hline Point & Time period & Data points & $\begin{array}{c}\text { 50th percentile } \\
\left(\mathrm{ms}^{-1}\right)\end{array}$ & $\begin{array}{c}\text { 95th percentile } \\
\left(\mathrm{ms}^{-1}\right)\end{array}$ & Point & Time period & Data points & $\begin{array}{c}\text { 50th percentile } \\
\left(\mathrm{ms}^{-1}\right)\end{array}$ & $\begin{array}{l}\text { 95th percentile } \\
\left(\mathrm{ms}^{-1}\right)\end{array}$ \\
\hline \multirow{2}{*}{ P1 } & Summer & 3294 & 0.059 & 0.140 & \multirow{2}{*}{ P11 } & Summer & 3294 & 0.062 & 0.141 \\
\hline & Winter & 3110 & 0.064 & 0.153 & & Winter & 3110 & 0.069 & 0.154 \\
\hline \multirow{2}{*}{ P2 } & Summer & 3294 & 0.087 & 0.244 & \multirow{2}{*}{ P12 } & Summer & 3294 & 0.136 & 0.298 \\
\hline & Winter & 3110 & 0.101 & 0.273 & & Winter & 3110 & 0.128 & 0.303 \\
\hline \multirow{2}{*}{ P3 } & Summer & 3294 & 0.091 & 0.227 & \multirow{2}{*}{ P13 } & Summer & 3294 & 0.068 & 0.181 \\
\hline & Winter & 3110 & 0.099 & 0.245 & & Winter & 3110 & 0.071 & 0.192 \\
\hline \multirow{2}{*}{ P4 } & Summer & 3294 & 0.070 & 0.167 & \multirow{2}{*}{ P14 } & Summer & 3294 & 0.061 & 0.135 \\
\hline & Winter & 3110 & 0.074 & 0.187 & & Winter & 3110 & 0.064 & 0.134 \\
\hline \multirow{2}{*}{ P5 } & Summer & 3294 & 0.053 & 0.134 & \multirow{2}{*}{ P15 } & Summer & 3294 & 0.069 & 0.182 \\
\hline & Winter & 3110 & 0.059 & 0.138 & & Winter & 3110 & 0.074 & 0.177 \\
\hline \multirow{2}{*}{ P6 } & Summer & 3294 & 0.068 & 0.144 & \multirow{2}{*}{$\mathrm{P} 16$} & Summer & 3294 & 0.104 & 0.211 \\
\hline & Winter & 3110 & 0.067 & 0.153 & & Winter & 3110 & 0.095 & 0.225 \\
\hline \multirow{2}{*}{ P7 } & Summer & 3294 & 0.067 & 0.136 & \multirow{2}{*}{ P17 } & Summer & 3294 & 0.089 & 0.205 \\
\hline & Winter & 3110 & 0.072 & 0.166 & & Winter & 3110 & 0.099 & 0.249 \\
\hline \multirow{2}{*}{ P8 } & Summer & 3294 & 0.104 & 0.233 & \multirow{2}{*}{ P18 } & Summer & 3294 & 0.093 & 0.209 \\
\hline & Winter & 3110 & 0.106 & 0.256 & & Winter & 3110 & 0.099 & 0.242 \\
\hline \multirow{2}{*}{ P9 } & Summer & 3294 & 0.099 & 0.244 & \multirow{2}{*}{ P19 } & Summer & 3294 & 0.148 & 0.301 \\
\hline & Winter & 3110 & 0.104 & 0.253 & & Winter & 3110 & 0.157 & 0.320 \\
\hline \multirow{2}{*}{$\mathrm{P} 10$} & Summer & 3294 & 0.110 & 0.274 & \multirow{2}{*}{$\mathrm{P} 20$} & Summer & 3294 & 0.061 & 0.131 \\
\hline & Winter & 3110 & 0.131 & 0.290 & & Winter & 3110 & 0.064 & 0.149 \\
\hline
\end{tabular}


In statistical analysis, the standard deviation measures the data dispersion from the mean value as in Equation (1):

$$
S t d=\sqrt{E\left[(X-\mu)^{2}\right]},
$$

with $\mu=E[X]$ representing the mean value, where $\mathrm{E}$ is the expectation operator. $X$ represents a discrete random variable with the probability mass function $\mathrm{p}(\mathrm{x})$. Then the expected value will be:

$$
E(X)=\sum x_{i} p\left(x_{i}\right) .
$$

In probability theory and statistics, skewness is a measure of the symmetry distribution in a certain data set. The skewness value can be positive, negative or undefined. The skewness of a variable $X$ is defined as the third standardized moment:

$$
\text { Skew }=\frac{\mu_{3}}{\sigma^{3}},
$$

where $\mu_{3}$ is the third moment above the mean and the $k^{\text {th }}$ moment about the mean is defined as:

$$
\mu_{k}=E\left[(X-E[X])^{k}\right] .
$$

Kurtosis represents the relative concentration of the data in the centre versus in the tails of a frequency distribution when is compared with the normal distribution (which has a kurtosis value of 3 ). This is equal to the fourth moment around the mean divided by the square of the variance (or the fourth power of the standard deviation) of the distribution minus 3 .

$$
\text { Kurt }=\frac{\mu_{4}}{\sigma^{4}}-3 .
$$

Moreover, analyses regarding the 50th and 95th percentiles were performed for all the points, grouped by summer time and winter time.

Percentiles are generally used in order to characterize a frequency distribution. In special the 50th and the 95th percentiles are often considered to identify the median values and the maximum data distributions being unaffected by outward values which are distant from the rest of the data. Percentiles $\left(p_{i}\right)$ are computed as follows:

$$
p_{i}=100 \frac{i-0.5}{n},
$$

where $i$ represents the position inside the dataset that marks the percentile to be calculated and $\mathrm{n}$ is the total number of the values in the distribution.

A first conclusion that can be drawn from Table 1 is that the average current velocity values in the Black Sea are in general small. There are usually small variations between summer and winter periods. The most stable points regarding velocity variations appear to be $\mathrm{P} 1, \mathrm{P} 2$,
P3, P4, P5 and P6. As expected, the points P1-P12 have higher current velocities than the rest, due to their coordinates located on the Rim current. The points P13, P14 and P15, located inside the curve described by the Rim current, have smaller velocities than the ones situated on the Rim or on the two anticyclonic eddies. The smallest velocity values are the ones recorded for the point P20, situated in the northwestern shelf zone, an area with mostly calm waters where no significant circulation feature was observed.

\section{Directional Distributions of the Current Velocity}

The rose type graphics are used to give a more comprehensive picture of how current speeds and directions are distributed in a particular point. Using a polar coordinate system for gridding the frequency of the currents over the time period is plotted by current direction, with color bands showing current velocity ranges. The direction of the longest spoke shows the current direction with the greatest frequency. Each concentric circle represents a different frequency, starting from zero at the center with increasing frequencies at the outer circles. In Figures 3 and 4 rose graphics were drawn for the 20 reference points. Figure 3 presents rose graphics for the winter time, where winter is considered the time frame from October to March, while Figure 4 presents the rose graphics for the summer time (April to September).

By comparing Figure 3 and Figure 4, it can be observed that there are significant changes between winter and summer time in current orientation, however these changes do not apply to all the points. P1, P5, P6, P11 and P13 present mostly the same structures for both time frames.

\section{Comparisons against in Situ Data}

For the Black Sea some current measurements were available for the time period 2002-2009 and they were compared against the corresponding satellite data provided by Aviso. The measurements were taken at the Gloria drilling platform located on the western side of the Black Sea, near the Romanian coasts at $44^{\circ} 31^{\prime} \mathrm{N}, 29^{\circ} 34^{\prime} \mathrm{E}$, every six hours. The data were then computed to a daily average, to fit the satellite data profile. The comparison between the satellite data and the measurements at the Gloria drilling platform in the Black Sea shows that the in situ measured current velocity values are usually higher than the satellite data with a bias of $0.077 \mathrm{~ms}^{-1}$. Table 4 presents some statistical parameters as mean values, bias, RMS error, SI (scatter index) and r (correlation coefficient).

With $X_{i}$ representing the measured values at the Gloria drilling platform, $Y_{i}$ the corresponding satellite data values and $\mathrm{n}$ the number of data points considered, the 


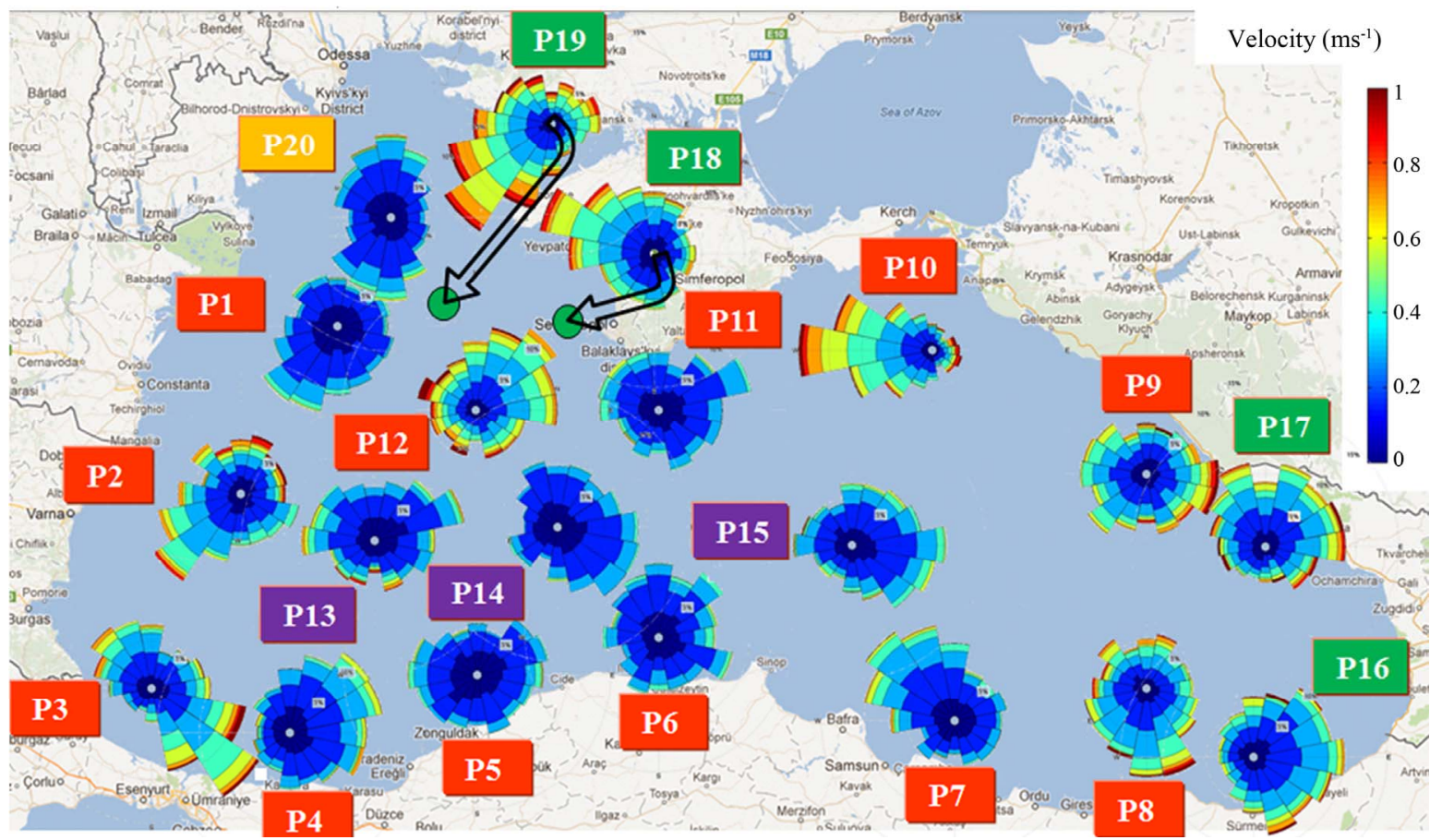

Figure 3. Current velocity roses for the reference points, winter time.

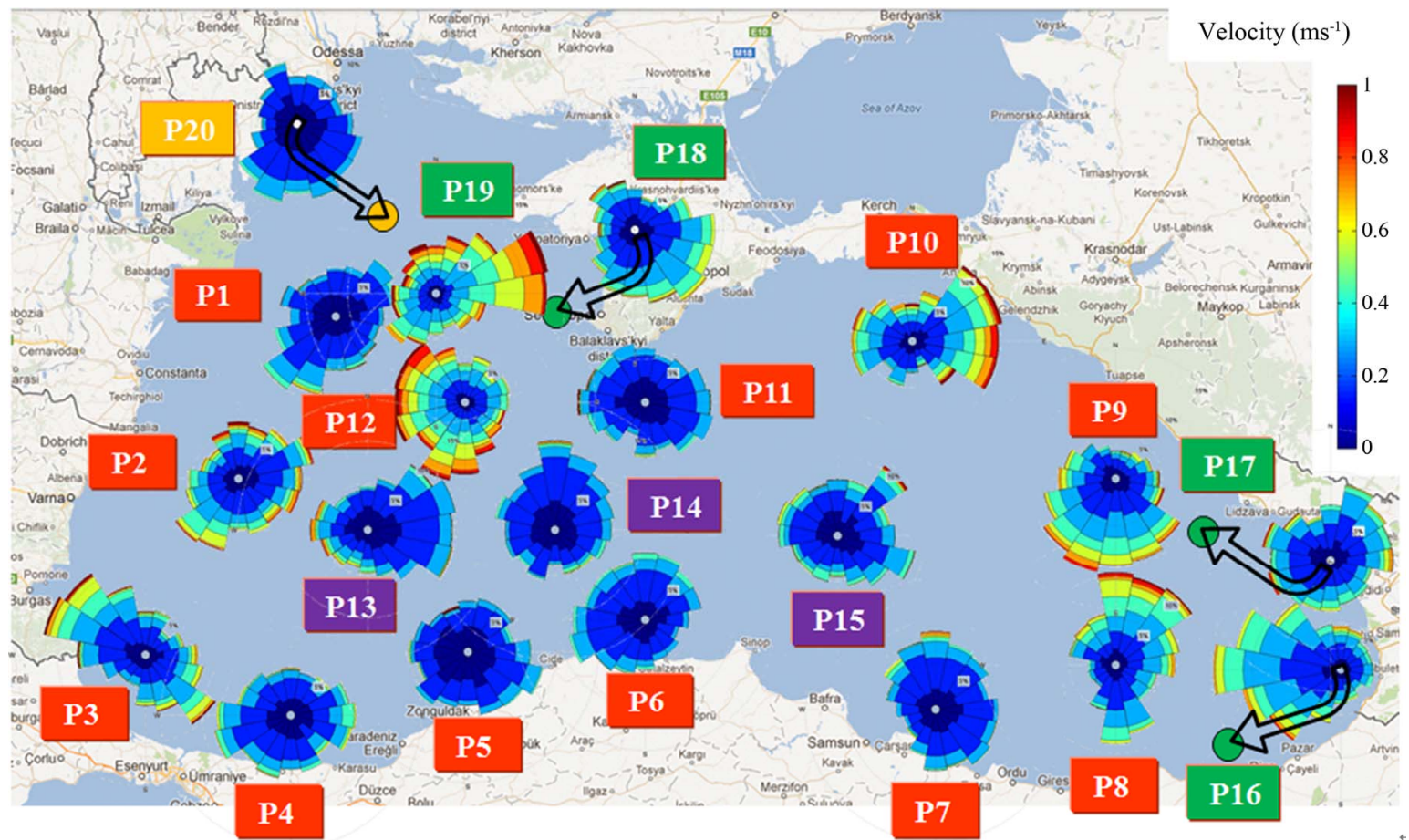

Figure 4. Current velocity roses for the reference points, summer time.

Table 4. Comparison between in situ measurements at the Gloria drilling platform and satellite data for the period 2002-2009.

\begin{tabular}{ccccccc}
\hline Point & $X_{\text {med }}\left(\mathrm{ms}^{-1}\right)$ & $Y_{\text {med }}\left(\mathrm{ms}^{-1}\right)$ & Bias $\left(\mathrm{ms}^{-1}\right)$ & RMSE & SI & $\mathrm{R}$ \\
\hline $\mathrm{G}$ & 0.195 & 0.077 & 0.117 & 0.147 & 0.75 & -0.025
\end{tabular}

statistical evaluated are defined by the following relationships:

$$
X_{\text {med }}=\tilde{X}=\frac{\sum_{i=1}^{n} X_{i}}{n}
$$




$$
\begin{gathered}
\mathrm{Bias}=\frac{\sum_{i=1}^{n}\left(X_{i}-Y_{i}\right)}{n}, \\
\mathrm{RMSE}=\sqrt{\frac{\sum_{i=1}^{n}\left(X_{i}-Y_{i}\right)^{2}}{n},} \\
\mathrm{r}=\frac{\mathrm{SI}=\frac{\mathrm{RMSE}}{\tilde{X}},}{\left(\sum_{i=1}^{n}\left(X_{i}-\tilde{X}\right)\left(Y_{i}-\tilde{Y}\right)\right.} \\
\left(\sum_{i=1}^{n}\left(X_{i}-\tilde{X}\right)^{2} \sum_{i=1}^{n}\left(Y_{i}-\tilde{Y}\right)^{2}\right)^{\frac{1}{2}}
\end{gathered}
$$

\section{Discussions}

According to satellite data the maximum current velocity is of $0.626 \mathrm{~ms}^{-1}$ and it belongs to P17, the point located at the edge of the Batumi eddy, closely followed by P19 with $0.588 \mathrm{~ms}^{-1}$ situated at the edge of the Sevastopol eddy, and P12 with $0.558 \mathrm{~ms}^{-1}$, situated on the Rim current. Except for the points P4 and P6, the current velocities recorded on the Rim current are higher than the ones recorded inside. The minimum values are close to zero for all the points, while the mean values vary from 0.068 $\mathrm{ms}^{-1}$ for P14 to $0.160 \mathrm{~ms}^{-1}$ for P19. The median values ranges from $0.056 \mathrm{~ms}^{-1}$ for P5 to $0.151 \mathrm{~ms}^{-1}$ for P19. Higher values for the standard deviation suggest that the data is spread out compared to the mean values. A zero value for the skewness suggests that the values are relatively evenly distributed on both sides of the mean value while a positive skew indicates that the tail on the right side of the probability density function is longer than the left side and the bulk of values lie to the left of the mean, this being the case here where the skewness values range from 0.742 (P6) to 0.699 (P17). Kurtosis represents the relative concentration of the data in the center versus the tails of the frequency distribution when is compared to the normal distribution that has a kurtosis value of 3 . In the present work the values of the kurtosis vary from 3.420 to 10.306 .

For the winter time the point P1 is oriented towards south-west, feature that is preserved for the summer time, with a small peak added oriented towards north-east. Point P2 in the winter time shows also a south-west clear orientation, while for the summer this decreases, a peak oriented north-west being also added. Regarding P3, strong differences between winter and summer time can be observed. While in the winter is showing a strong south-east orientation, for the summer time this changes to north-west. P4 is showing a small north-east orientation for the winter time, while for summer is difficult to pinpoint a definite direction, with two small peaks oriented west and east. P5 shows little differences in current orientation between summer and winter, also with no definite direction. The same case applies also for P6 where is also difficult to identify a direction, with the observation that while in the summer time it presents a stable radial structure, small peaks in all directions can be observed in the winter. P7 presents 5 peaks clearly oriented north-west in the winter time, while in the summer there is also no definite direction. As well as for P3, P8 presents major differences between winter and summer time. While in the winter is oriented towards south, this changes drastically in the summer time, when a strong north-east component appear, accompanied by a small peak oriented towards south. For the point P9 is difficult to pinpoint a clear orientation in the winter: it appears to be oriented towards east, but there's no clear direction. For the summer time most of the peaks are oriented south. Major differences can also be observed for P10: in the winter time there is a clear west orientation, fact that changes in the summer when an east orientation appear, with small reminiscences from the winter feature. P11 point seems to preserve most of its features between the seasons, although in the winter there is a small north-east component that in the summer disappears. Regarding the P12 point, major differences can be observed: in the winter there is a strong component oriented north-east, while in the summer the general direction is split in two: a south-south-west component and a west one. Due to their position inside the Rim current, it wasn't expected to see important changes between summer and winter time for the points P13, P14 and P15, however there are small differences, especially for P15 located at the edge of the Eastern Gyre. Points P16, P17, P18 and P19 are located at the edge of the Batumi (P16, P17) and Sevostok (P18, P19) eddies. These are two of the biggest nearshore anticyclonic eddies present in the Black Sea, and are characterized by high velocities and strong seasonal differences, fact confirmed by the present analysis. In the winter time P16 is split into multiple directions, mostly oriented east, while in the summer there is a definite west orientation, with high peaks. P17 presents a higher turbulence for the winter time, with no definite direction, but mostly oriented north, east and west. This feature changes for the summer time when a north-east component appears, along with a smaller one towards north-west. For P18 in the winter a strong northwest orientation can be observed, while in the summer this changes towards south-east. Also P19 presents important differences between seasons with a strong component oriented south-west in the winter that changes to a north-east in the summer time. Seasonal variations can also be observed in P20, the point located outside the general features of the Black Sea, in the northwestern 
shelf area. While in the winter two dominant directions are present: north and south, for the summer there is a general orientation south.

\section{Conclusions}

As expected, most of the points located on the Rim cyclonic current and on the nearshore anticyclonic eddies have higher velocities than the ones located in the central gyres or northwestern shelf area. Also, they are described by a higher instability regarding current speed and direction on the seasonal changes.

Higher value for kurtosis as the ones registered at points P5 (10.307), P17 (8.979), P13 (6.570) and P11 (6.219) means that in these cases there is a strong possibility that higher velocities than usual will appear.

A similar study with the emphasis on the anticyclonic and cyclonic eddies, was treated in [18]. The implementation of a global circulation modeling system for the Black Sea basin was presented by Toderascu and Rusu in [19]. Also, the subject of modeling of wave-current interactions at the Danube mouths was treated by Rusu in [20]. Another work that needs to be mentioned here is the work of Rusu and Macuta regarding the numerical modeling of long shore currents in marine environment [21], as well as the work of $\mathrm{L}$. Rusu regarding the application of numerical models to evaluate oil spills propagation in the coastal environment of the Black Sea [22].

\section{Acknowledgements}

The work of the first author has been made in the scope of the project EFICIENT (Management System for the Fellowships Granted to the Ph.D. Students) supported by the Project SOP HRD-EFICIENT 61445/2009. The altimeter products were produced by Ssalto/Duacs and distributed by Aviso with support from Cnes.

This work was also supported by a grant of the Romanian Ministry of National Education, CNCS-UEFISCDI PN-II-ID-PCE-2012-4-0089 (project DAMWAVE).

\section{REFERENCES}

[1] D. M. Filippov, "The Cold Intermediate Layer in the Black Sea,” Oceanology, Vol. 5, No. 1, 1965, pp. 47-52.

[2] D. Tolmazin, "Changing Coastal Oceanography of the Black Sea in Northwestern Shelf," Progress in Oceanography, Vol. 15. No. 4, 1985, pp. 217-276. doi:10.1016/0079-6611(85)90038-2

[3] I. M. Ovchinnikov and Yu. I. Popov, "Evolution of the Cold Intermediate Layer in the Black Sea," Oceanology, Vol. 27, No. 3, 1987, pp. 555-560.

[4] C. E. Enriquez, "Mesoscale Circulation in the Black Sea: A Study Combining Numerical Modelling and Observations," Ph.D. Thesis, University of Plymouth, Devon, 2005, 257p.
[5] L. Mee and O. Maiboroda, "Black Sea Study Pack: A Resource for Teachers," Black Sea Ecosystem Recovery Project, Vienna, 2006, 87p.

[6] N. M. Knipovich, "The Hydrological Investigations in the Black Sea Area," Trudy Azova-Chernomorskoy Nauchnopromyslovoy Ekspeditsii, Vol. 10, No. 10, 1932, 274p. (in Russian)

[7] Filipov, "Circulation and Structure of the Waters in the Black Sea," Nauka, Moscow, 1968, 136p.

[8] S. G. Boguslavskiy and A. S. Sarkisyan, T. Z. Dzhioyev and L. A. Koveshnikov, "Analysis of Black Sea Current Calculations," Izvestiya Atmospheric and Oceanic Physics, No. 12, 1976, pp. 205-207.

[9] A. S. Blatov, N. P. Bulgakov, V. A. Ivanov, A. N. Kosarev and V. S. Tuljulkin, "Variability of the Black Sea Hydrophysical Fields," Gydrometeoizdat, Leningrad, 1984, 240p.

[10] E. V. Stanev, D. Truhchev and V. Roussenov, "Black Sea Circulation and Its Numerical Modeling," St. Kliment Ohridski University Press, Sofia, 1984, 222p.

[11] E. V. Stanev, "On the Mechanisms of the Black Sea Circulation," Earth Science Reviews, Vol. 28, No. 4, 1990, pp. 285-319. doi:10.1016/0012-8252(90)90052-W

[12] V. N. Eremeev, A. V. Ivanov and V. S. Tuljulkin, "Climatic Interannual Variability of Geostrophic Circulation in the Black Sea," Ukrainian Academy of Sciences, Kyiv, 1991, 53p.

[13] T. Oguz, V. S. Latun, M. A. Latif, V. V. Vladimirov, H. I. Sur, A. A. Markov, E. Ozsoy, B. B. Kotovchchikov, V. V. Eremeev and U. Unluata, "Circulation in the Surface and Intermediate layers of the Black Sea," Deep Sea research I, Vol. 40, No. 8, 1993, pp. 1597-1612. doi:10.1016/0967-0637(93)90018-X

[14] T. Oguz, M. A. Latif, H. I. Sur, E. Ozsoy and U. Unluata, "The Black Sea Circulation: Its Variability as Inferred from Hydrographic and Satellite Observations," Journal of Geophysical Research: Oceans, Vol. 97, No. C8, 1992, pp. 12569-12584. doi:10.1029/92JC00812

[15] J. Staneva, D. Dietrich, E. Stanev and M. Bowman, "Rim Current and Coastal Eddy Mechanisms in an Eddy-Resolving Black Sea General Circulation Model," Journal of Marine Systems, Vol. 31, No. 1-3, 2001, pp. 137-157. doi:10.1016/S0924-7963(01)00050-1

[16] G. Korotaev, T. Oguz, A. Nikiforov and C. Koblinsky, "Seasonal, Interannual, and Mesoscale Variability of the Black Sea Upper Layer Circulation Derived from Altimeter Data," Journal of Geophysical Research, Vol. 108, No. C4, 2003, p. 3122. doi:10.1029/2002JC001508

[17] http://www.aviso.oceanobs.com/en/

[18] R. Toderascu and L. Rusu, "Study on the Currents Variability and Patterns in the Black Sea," 12th International Multidisciplinary Scientific GeoConference SGEM 2012, 17-23 June 2012, pp. 825-832.

http://sgem.org/sgemlib/spip.php?article2190

[19] R. Toderascu and E. Rusu, "Implementation of a Global Circulation Modeling System for the Black Sea Basin," 12th International Multidisciplinary Scientific GeoConference SGEM 2012, 17-23 June 2012, pp. 739-746. 
http://sgem.org/sgemlib/spip.php?article2179\&lang=en

[20] E. Rusu, "Modeling of Wave-Current Interactions at the Danube Mouths," Journal of Marine Science and Technology, Vol. 15, No. 2, 2010, pp 143-159. doi:10.1007/s00773-009-0078-x

[21] E. Rusu and S. Macuta, "Numerical Modelling of Longshore Currents in Marine Environment," Environmental
Engineering and Management Journal, Vol. 8, No. 1, 2009, pp. 147-151.

[22] L. Rusu, "Application of Numerical Models to Evaluate Oil Spills Propagation in the Coastal Environment of the Black Sea," Journal of Environmental Engineering and Landscape Management, Vol. 18, No. 4, 2010, pp. 288295. doi: $10.3846 /$ jeelm.2010.33 